\title{
Anti-tubercular activity and mutagenicity of bioactive compounds in culture broth (CBPs) of Streptomyces lydicus A2
}

\author{
Monthon Lertcanawanichakul ${ }^{1,2 \star}$, Kittisak Chawawisit ${ }^{1,2}$, \\ Nattida Damnadee ${ }^{1}$, Natnithi Thiengtham ${ }^{1}$ and Nisarat Rittirak ${ }^{1}$
}

\author{
${ }^{1}$ School of Allied Health Sciences, Walailak University, Nakhon Si Thammarat 80161, \\ Thailand \\ ${ }^{2}$ Research Unit Natural ProductsUtilisation, Walailak University, Nakhon Si Thammarat \\ 80161, Thailand
}

\begin{abstract}
Secondary metabolites (active metabolites) that produced from Streptomyces lydicus A2 excreted to culture broth is a potential molecules candidate due to its anti-MRSA activity and other biological activities. Interesting in the scope of the antibiotic, we have checked the biological activities like effect of secondary metabolites collected from culture broth (CBPs) on Mycobacterium tuberculosis H37Ra by green fluorescent protein (GFP)based fluorescent detection, including their mutagenic effect. In this study, the minimum inhibitory concentration (MIC) of CBPs against M. tuberculosis H37Ra was found to be 130 $\mu \mathrm{g} / \mathrm{mL}$ of protein content $(\mu \mathrm{g}$ protein $/ \mathrm{mL}$ ). When compared with known antituberculous drugs like rifampicin, isoniazid, ethambutol and streptomycin, CBPs showed higher MIC on $M$. tuberculosis H37Ra. The mutagenic effect of CBPs was performed by Ames test. CBPs was non-mutagenic up to $130 \mu \mathrm{g}$ protein/mL concentration.
\end{abstract}

Keywords : Ames test; Mutagenicity; Bioactive compounds; Streptomyces lydicus.

\section{Introduction}

Over the last two decades, exploring the possibility of developing new classes of antimicrobial compounds has emerged prominently due to pathogens acquired resistance to emerging antibiotics. Presently available antimicrobial compounds are getting old and less efficient, only few truly original replacements are available ${ }^{1}$.Therefore, screening and characterization of the novel antimicrobial compounds especially, peptides from microorganisms, have drawn attention ${ }^{2}$. Actinobacteria especially, species of the genus Streptomyces are reported to show complex metabolic machinery that can produce an infinite variety of secondary metabolites, including dark-brown to black melanoid pigments, that is not only play important ecological roles in the immediate environment ${ }^{3-4}$, but also play important in pharmaceutical/medical industries ${ }^{5-7}$ concerning in drugbased discovery. There are many species of Streptomyces that can produce the secondary metabolites showing antimicrobial activity ${ }^{3,6}$. As apparently $99 \%$ of the microbial species are still unexplored ${ }^{8}$. Therefore, possibility of discovering actinobacteria producing potent still remains. S. lydicus is one of many species of Streptomyces 
is reported to produce active metabolites can inhibit the growth of fungi ${ }^{9}$.In our search for bioactive compounds active against methicillin resistant Staphylococcus aureus (MRSA), S. lydicus A2, was isolated from air, which also produced active metabolites ${ }^{10}$. Interest was concerned on active metabolite from strain A2, due to recent reports of its antioxidant activity, it is speculated to be a possible drug candidate. By the way, the active metabolites from Streptomyces may cause cancer by inducing changes in the sequence of the genetic material (mutation), in particular, if they result in germ line mutations which can be inherited through generations. Hence, the identification of such mutagens is an important first step in improving active metabolites safely use for human health. Carcinogenicity and mutagenicity are among the toxicological effects that cause the highest concern for human health; thus, they are the object of intense research activity, as well as of recognized regulatory testing methods ${ }^{11}$. Improving inexpensive, quick and simple methodologies to identify potential mutagens by using bacterial strains ${ }^{12}$. To date, there are several bacterial strains known to show sensitivity to a wide range of mutagens ${ }^{13}$. In addition, the inability to synthesize cytochrome P450 mediated products makes them suitable for the analysis of potential mutagens ${ }^{14}$. A well established method of determining the potential mutagenic nature of a substance in a bacterial system is the Ames test which uses different strains of Salmonella typhimurium $^{14-16}$. In the present study was aimed at description of bioactive compounds produced by Streptomyces lydicus A2 on Mycobacterium tuberculosis in comparison to standard drugs, along with mutagenic activity by Ames test using S. typhimurium TA100 as test strain.

\section{Materials and Methods}

\section{Chemicals}

Dimethyl sulfoxide (DMSO), nicotinamide adenine dinucleotidephosphate sodium salt(NADP),Dglucose-6-phosphate disodium salt, magnesium chloride, L-histidine monohydrate, D-biotin, 4-nitroquinoline1-oxide were purchased from Sigma Chemical Co. (St. Louis, MO, USA). Oxoid Nutrient Broth No. 2 (Oxoid, Basingstoke, HAM, UK) and Bacto Agar (BD Bacto ${ }^{\mathrm{TM}}$, Sparks, MD, USA) were used as bacterial media. DGlucose, magnesium sulfate, citric acid monohydrate, anhydrous dibasic potassium phosphate, sodium ammonium phosphate, monobasic sodium phosphate, dibasic sodium phosphate and sodium chloride were purchased from Merck (Whitehouse Station, NJ, USA).

\section{Starter culture}

Streptomyces lydicus $\mathrm{A} 2^{10}$ (TISTR), deposited in the GenBank database accession number KF712383.1, was isolated from air at Sciencetific and Technological Equipments Building $7^{\text {th }}$, Walailak University, Thailandby the Biosampler, Microflow90 (Aquaria), at flow rate $100 \mathrm{~L} / \mathrm{min}$ for $30 \mathrm{~min}$ according to manufacture's instruction. Pure culture was kept in $15 \%$ glycerol at $-80^{\circ} \mathrm{C}$ storage.

\section{Cultivation and collection of culture broth maintained bioactive compounds (CBPs)}

Medium and incubation time for S. lydicus A2production was carried out by LB/2 (yeast extract 2.5 $\mathrm{g} / \mathrm{L}$, tryptone $5 \mathrm{~g} / \mathrm{L}, \mathrm{NaCl} 5 \mathrm{~g} / \mathrm{L}$ ) medium. Theseed culture was prepared by inoculation of 1 colony in $10 \mathrm{ml}$ of $\mathrm{LB} / 2$ liquid media and incubated in shaker incubator (Cocono, Taiwan) at $200 \mathrm{rpm}, 30{ }^{\circ} \mathrm{C}$ for 3 days.Furthermore, the $1 \%$ of seed culture was inoculated into $100 \mathrm{ml}$ of liquid media in $500-\mathrm{mL}$ Duran bottle containing 50 glass beads andincubated on shaker incubator at $200 \mathrm{rpm}$ for certain time (10-12 days). Finally,the CBPs was harvested by centrifuged at $12,000 \mathrm{rpm}, 4{ }^{\circ} \mathrm{C}$ for $20 \mathrm{~min}$, filtrated through millipore membrane, pore size $0.45 \mu \mathrm{m}$, for sterilization. It was used to test anti-tubercular (anti-TB) activity and mutagenicity assay.

\section{Bradford protein assay ${ }^{17}$}

Bradford reagent concentrate was purchased from Bio-Rad. The concentrated reagent was diluted 1:4 and filter through Whatman no. 1 paper just before use. The Bradford reagent (working solution) should be a light brown in color. Filtration may have to be repeated to rid the reagent of blue components. The spectrophotometer was warmed up before use. The $20 \mu \mathrm{L}$ of culture broth that collected from strain A2 was mixed thoroughly in working solution $(1 \mathrm{~mL})$, stand still at room temperature for $5 \mathrm{~min}$, measured the absorbance at $595 \mathrm{~nm}$. The bovine serum albumin (BSA) at the concentration of $0.2-1 \mathrm{mg} / \mathrm{mL}$ was used as 
standard for setting calibrating curve and determined amounts of protein from the curve. The concentration of original samples was determined from the amount protein, volume/sample, and dilution factor, if any.

\section{Effect of bioactive compounds on Mycobacterium tuberculosis, H37Ra}

Green fluorescent protein (GFP) expressing Mycobacterium tuberculosis strain H37Ra was established by Changsen, et al. $(2003)^{18}$. Anti-TB was analysed by green fluorescent protein (GFP)-based fluorescent detection $^{19}$. The test was done at BIOTECH Thailand. H37Ra $g f p$ is cultivated on 7H10 agar containing 30 $\mu \mathrm{g} / \mathrm{mL}$ kanamycin at $37^{\circ} \mathrm{C}$ for 4 weeks or until growth is observed. Starter cultures are prepared by fully looping 2-3 single colony into $7 \mathrm{H} 9$ broth supplemented with $0.2 \% \mathrm{v} / \mathrm{v}$ glycerol, $0.1 \% \mathrm{w} / \mathrm{v}$ of casitone, $0.05 \%$ $\mathrm{v} / \mathrm{v}$ Tween 80, 10\% v/v Middlebrook OADC enrichment solution (BD Biosciences) and $30 \mu \mathrm{g} / \mathrm{mLof}$ kanamycin. The mixture was then then incubated at $37^{\circ} \mathrm{C}$ in $200 \mathrm{rpm}$ shaker incubator until the optical density (OD) at $550 \mathrm{~nm}$ is between 0.5 and 1 . For batch cultivation, the starter cultures are transferred at the rate of $1 / 10$ volume to the $7 \mathrm{H} 9$ broth and incubated at $37^{\circ} \mathrm{C}$ in $200 \mathrm{rpm}$ shaker incubator until the OD550 nm is approximately 0.5 to 1 . The cells are pelleted, washed and suspended in phosphate buffer (PBS), and then sonicated 8 times for 15 seconds each. The sonicated samples are then aliquoted and frozen at $-80^{\circ} \mathrm{C}$ for up to 2 to 3 months prior to use. Titer stocks are determined by colony forming unit (cfu) assay and the seeding density for anti-TB assay is optimized by serial dilutions. The dilution that grows at logarithmic phase on day 10 will be used as an optimal bacterial seeding density. For assay in 384-well format, the seeding is approximately $1 \times 10^{5}$ $\mathrm{cfu} / \mathrm{mL}$ per well. The assay is performed in quadruplicate wells; each well containing $5 \mu \mathrm{L}$ of serially dilute(diluted in 5\% dimethyl sulfoxide) of CBPs, followed by $45 \mu \mathrm{L}$ of cell suspension prepared as described above. Plates were incubated at $37^{\circ} \mathrm{C}$ for 10 days and the fluorescence signals are measured using SpectraMax M5 microplate reader (Molecular Devices, USA) in the bottom-reading mode at the excitation and emission wavelengths of $485 \mathrm{~nm}$ and $535 \mathrm{~nm}$. Fluorescence signals on day zero are used as background, which is used to subtract the signals on day 10 . The Percentage of growth inhibition is calculated from the mean of fluorescence unit of cells treated with sample $\left(\mathrm{FU}_{\mathrm{T}}\right)$ and untreated cells $\left(\mathrm{FU}_{\mathrm{C}}\right)$, as the following equation: \% Inhibition $=[\mathbf{1 -}$ $\left.\left(\mathbf{F U}_{\mathbf{T}} / \mathbf{F U}_{\mathbf{C}}\right)\right] \times \mathbf{1 0 0}$. The lowest drug concentration that inhibits cell growth by $90 \%$ is reported as the Minimum Inhibitory Concentration (MIC). Rifampicin, Ofloxacin, Streptomycin, Isoniazid and Ethambutol are used as positive controls, and $0.5 \%$ DMSO is used as a negative control.

\section{Confirmation of S. typhimurium TA100 Genotype}

Prior to performing the mutagenicity assay, S. typhimurium TA100 mutation was confirmed. The strain was grown on a nutrient agar No.2 (Difco) plate, and the genotype was checked for its histidine auxotrophy, deep rough ( $r f a$ ) character, UV sensitivity ( $u v r B$ mutation,) and the presence of the $\mathrm{R}$ factor plasmid. Pure samples were stored at $-80^{\circ} \mathrm{C}$. This strain requires histidine to grow, and in the absence of an external histidine source, cells cannot grow to form colonies. The presence of the $u v r B$ mutation makes the strain sensitive to UV light. The $r f a$ mutation changes the properties of the bacterial cell wall and causes a defective lipopolysaccharide (LPS) layer that coats the bacterial surface, making the bacteria more permeable to larger molecules. The $r f a$ mutation is indicated by sensitivity to crystal violet. The presence of $\mathrm{R}$ factor plasmid in this strain shows that they are resistant to ampicillin ${ }^{14-16}$.

\section{Preliminary toxicity test of the appropriate concentration of CBPs for the Ames Test}

S. typhimurium TA100 was cultured in the presence of different protein concentrations of bioactive compounds. This assay also included positive (bacteria without bioactive compounds) and negative (bioactive compounds without bacteria) controls.

\section{Metabolic Activation System (S9 Mixture)}

The S9 fraction was purchased from Sigma-Aldrich (USA). The metabolic activation system consisted of $4 \%$ of S9 fraction, $1 \%$ of $0.4 \mathrm{M} \mathrm{MgCl}_{2}, 1 \%$ of $1.65 \mathrm{M} \mathrm{KCl}, 0.5 \%$ of $1 \mathrm{M}$ D-glucose-6-phosphate disodium and $4 \%$ of $0.1 \mathrm{M} \mathrm{NADP}, 50 \%$ of $0.2 \mathrm{M}$ phosphate buffer and $39.5 \%$ sterile distilled water ${ }^{16}$.

\section{Mutagenicity assay using S. typhimurium TA100}

The protocol for the Salmonella/microsome assay, including the composition of themedia used and the S9 mix has been previously described ${ }^{15}$ using the Salmonella typhimurium strain TA100with and without 
metabolization by the pre-incubation method ${ }^{16}$.The strains from frozen cultures were grown overnight for $12-$ $14 \mathrm{~h}$ in Oxoid Nutrient Broth No. 2. The metabolic activation mixture (S9) was freshly prepared before each test. Three different doses of test compounds were assayed. All of them were diluted in DMSO. The concentrations were selected on the basis of apreliminary toxicity test.In all subsequent assays, the upper limit of the dose range tested was eitherthe highest non-toxic dose or the lowest toxic dose determined in this preliminary assay. The various concentrations of CBPs to be tested were added to $0.5 \mathrm{ml}$ of $0.2 \mathrm{M}$ phosphate buffer $(\mathrm{pH} 7.4)$ or with $0.5 \mathrm{~mL}$ of $4 \% \mathrm{~S} 9$ mixture and $0.1 \mathrm{ml}$ of bacterial culture $\left(1 \times 10^{9} \mathrm{cfu} / \mathrm{mL}\right)$ and then incubated at $37{ }^{\circ} \mathrm{C}$ for $20-30 \mathrm{~min}$. After thistime, $2 \mathrm{~mL}$ of top agar supplemented with $0.1 \mathrm{~mL}$ of histidinebiotin solution at $45{ }^{\circ} \mathrm{C}$ was added to the mixture and poured on to a plate containing minimal agar. The plates were incubated at $37{ }^{\circ} \mathrm{C}$ for $48 \mathrm{~h}$ and the revertant colonies were counted manually. All experiments were analyzed in triplicate. Positive and negative controls were also included in the assay. The negative control contained bacteria, a histidine-biotin solution and sterile distilled water, and it was used for the purpose of monitoring the rate of spontaneous mutations. The positive control included bacteria, a histidine-biotin solution and the well-known mutagen, 4-nitroquinoline-1-oxide. These were also plated on agar plates containing glucose and minimal medium, and the plates were incubated at $37^{\circ} \mathrm{C}$ for 48 hours. Following the incubation, the number of revertant colonies (spontaneous histidine revertant)was manually counted in all plates.

The mutagenic index (MI) was also calculated for each concentration tested, this being the average number of revertants per plate with the test compound divided by the average number of revertants per plate with the negative (solvent) control. A sample was considered mutagenic when a dose-response relationship was detected and a two-fold increase inthe number of mutants (MI $\geq 2$ ) was observed with at least one concentration $^{20}$. A MI value of $\geq 2$ is indicative of a mutagen, while a value of 1.7 to 1.9 indicates a potential mutagen and a value of $\leq 1.6$ is considered non-mutagenic ${ }^{21-22}$.

\section{Results and Discussion}

Actinomycetes are also the focus of attention due to their production of secondary metabolites that may have a range of pharmaceutical and biotechnological applications ${ }^{23}$. Streptomycetes especially the genus Streptomyces were very potent producers of secondary metabolites including antibacterial enzymes and toxins $^{24}$, due to toxicity of the molecule not much work was subsequently. The identification of such mutagens is an important first step in improving active metabolites safely use for human health.

\section{Anti-TB activity}

This study was found that the CBPs contained a protein contents at a concentration of $1.06 \mathrm{mg}$ protein/mL determined by Bradford method. It was used to analyse anti-TB activity by means of GFP-based fluorescent detection. The incubation period was for 10 days as described in topic "Effect of bioactive compounds on Mycobacterium tuberculosis, H37Ra". Various concentrations of drugs or CBPs were two-fold serially prepared and tested. The inhibitory activity after the treatments with various concentration of drugs or CBPs observed in $M$. tuberculosis H37Ra. The tested concentrations of various drugs varied from $0.025 \mu \mathrm{g} / \mathrm{mL}$ to $3.75 \mu \mathrm{g} / \mathrm{mL}$ for all the drugs. Whereas, the concentrations of CBPs varied from $12.5 \mu \mathrm{g}$ protein $/ \mathrm{mL}$ to 200 $\mu \mathrm{g}$ protein $/ \mathrm{mL}$. The inhibitory was observed at $100 \mu \mathrm{g}$ protein $/ \mathrm{mL}$ for CBPs, whereas for rifampicin, streptomycin, isoniazid, ofloxacin and ethambutol was observed at $0.025 \mu \mathrm{g} / \mathrm{mL}, 0.625 \mu \mathrm{g} / \mathrm{mL}, 0.047 \mu \mathrm{g} / \mathrm{mL}$, $0.781 \mu \mathrm{g} / \mathrm{mL}$ and $1.87 \mu \mathrm{g} / \mathrm{mL}$, respectively.

The CBPs and reference standards showed inhibitory activity against M. tuberculosis H37Ra. The results indicated that CBPs was also effective against the tested strain H37Ra when compared with other drug tested. However, the mechanisms of action have to concerned for further study.

\section{Mutagenicity assay using S. typhimurium TA100}

The purpose of testing the mutagenicity effect of CBPs by Ames test was to find out its possibility as a potential carcinogen/mutagen. Carcinogenicity and mutagenicity are among the toxicological effects that cause the highest concern for human health. S. typhimurium TA100 carries a specific mutation in its histidine operon, and thus is incapable of synthesizing the amino acid histidine (His), whereas the wild type strain is prototroph (His+), and can do so when provided with ammonium phosphate and a suitable carbon source such as glucose. In addition to His auxotrphy, the TA100 strain carries both $r f a$ and uvrB-bio mutations. The $r f a$ mutation 
changes the properties of the bacterial cell wall by resulting in a defective lipopolysaccharide (LPS) layer that coats the bacterial surface, making the bacteria more permeable to larger molecules, while the uvrB-bio mutation makes the strain sensitive to UV light (unable to repair damaged DNA) and confers a biotin auxotrophy. Finally, this strain carries a mutation that enhances R-factor plasmid pKM101 activity which confers ampicillin resistance ${ }^{15}$.S. typhimurium TA 100 used in the Ames test is auxotroph (His-), and when grown in solid media containing a minimum amount of histidine along with a potential mutagen, only the bacteria with a reverse mutation in the His gene (revertants) are capable of growth and colony formation ${ }^{13-14}$. Results of S. typhimurium TA100 genotype confirmation are provided in Table $\mathbf{1}$, andthe appropriate concentration of CBPs for the Ames test was determined at $130 \mu \mathrm{g}$ protein $/ \mathrm{mL}$ (titer 1:8 from initial). Table 2 shows the mean number of revertants/plate (M), the standard deviation (SD) and the mutagenic index (MI) after the treatments with the CBPs, observed in S. typhimurium strain TA100 in the presence (+S9) and absence $(-\mathrm{S} 9)$ of metabolic activation. Both in the absence of the external metabolizing system, S9 mix, CBPs is not the mutagenic molecule, with a mutagenic index (MI) no more than 2.0 at the concentration of $65 \mu \mathrm{g}$ protein/mLper plate in strain TA100. Mutagenicity analyse by Ames test for secondary metabolites produced from Streptomyces species still not much work was investigated. There are reportsof secondary metabolites, lipopeptide from $S$. amritsarensis ${ }^{25}$ or borrelidin from $S$. rochei ${ }^{26}$. It was found to be non-mutagenic against Salmonella typhimurium. For $S$. lydicus was reported to produced active metabolites, natamycin, can inhibit the growth of fungi ${ }^{9}$. There is still no report about its secondary metabolites effect on S. typhimurium by Ames test. This study is concerned about mutagenicity activity of secondary metabolites of $S$. lydicus. It may be used as candidate for improving the drug-based discovery, however, cytotoxicity against other cell lines would concern.

Table 1- Confirmation of $S$. typhimurium TA100 genotype.

\begin{tabular}{|c|c|c|c|}
\hline Bacteria & \multicolumn{3}{|c|}{ Genotype } \\
\hline & R-factor ${ }^{1}$ & uvrB mutation ${ }^{2}$ & $r f a$ mutation ${ }^{3}$ \\
\hline S. typhimurium TA100 & + & + & + \\
\hline
\end{tabular}

${ }^{1}$ Resistance to ampicillin, indicative of the presence of the R-factor.

${ }^{2}$ Sensitivity to ultraviolet radiation, indicative of $u v r B$ mutation.

${ }^{3}$ Sensitivity to crystal violet, indicating $r f a$ mutation.

Table 2- Mutagenic activity expressed as the mean and standard deviation of the number of revertants/plate and the mutagenic index (MI), in bacterial strains TA 100 treated with CBPs from Streptomyces lydicus $\mathrm{A} 2$ at various doses, with (+S9) or without $(-\mathrm{S} 9)$ metabolic activation.

\begin{tabular}{|c|c|c|}
\hline $\begin{array}{l}\text { Treatment } \\
(\boldsymbol{\mu g} \text { protein/mL) }\end{array}$ & $\begin{array}{l}\text { Number of revertants per plate in } \boldsymbol{S} \text {. typhimurium TA100 } \\
(\mathbf{M} \pm \mathbf{S D}) \text { and Mutagenicity Index }(\mathbf{M I})\end{array}$ \\
\hline & $-\mathrm{S} 9$ & $+\mathrm{S} 9$ \\
\hline CBPs (130) & $40 \pm 0.6(0.74)$ & $65 \pm 15(1.41)$ \\
\hline Positive control & $1,567 \pm 100$ & $1.932 \pm 67$ \\
\hline
\end{tabular}

\section{Conclusion}

The study was successful in the investigation of antagonistic-and mutagenic- actinomycetes from air sample collected at Walailak University, Thailand. The isolate A2 was identified as S. lydicus that reported elsewhere ${ }^{10}$. It's bioactive compounds in culture broth (CBPs) exhibited anti-M. tuberculosisH37Ra and was non-mutagenic on S.typhimurium TA100.TheS. lydicus A2 can be a potential candidate for the development of therapeutic agents. Further studies on characterization of the purified bioactive components in the solvent extract are under progress.

\section{Acknowledgements}

The author(s) are grateful to the School of Allied Health Sciences, Walailak University for kindly prepared some instruments for experiments. This work was supported by Walailak University (WU60109). 
Monthon Lertcanawanichakul et al/International Journal of PharmTech Research, 2017,10(2): 89-95. 94

\section{Conflict of Interests}

The authors declare that there are no conflict of interests.

\section{References}

1. D.J. Payne, M.N. Gwynn, D.J. Holmes and D.L. Pompliano, Nat. Rev. Drug Discov., 6, 29 (2007); doi:10.1038/nrd2201.

2. G. Laverty, S.P. Gorman and B.F. Gilmore, Int. J. Mol. Sci., 12, 6566 (2011); doi:10.3390/ijms12106566.

3. G.L. Challis and D.A. Hopwood, Proc. Natl. Acad. Sci. USA, 100(Supplement 2), 14555 (2003); doi:10.1073/pnas.1934677100.

4. A. Fajardo and J.L. Martı'nez, Curr. Opin. Microbiol., 11, 161 (2008); doi:10.1016/j.mib.2008.02.006.

5. S. Naorungrote, W. Chunglok, M. Lertcanawanichakul and P. Bangrak, Walailak J. Sci. Technol., 8, 131 (2011).

6. R.E. de Lima Procópio, I.R. da Silva, M.K. Martins, J.L. de Azevedo and J.M. de Araújo, Braz. J. Infect. Dis., 16, 466 (2012); doi:10.1016/j.bjid.2012.08.014.

7. P. Kiruthika, S.D. Nisshanthini and J. Angayarkanni, Int. J. Pharma. Bio. Sci., 4, 127 (2013).

8. M.G. Watve, R. Tickoo, M.M. Jog and B.D. Bhole, Arch. Microbiol., 176, 386 (2001); doi:10.1007/s002030100345.

9. H.M. Atta, A.S. El-Sayed, M.A. El-Desoukey, M. Hassan and M. El-Gazar, J. Saudi Chem. Soc., 19, 360 (2015); doi:10.1016/j.jscs.2012.04.001.

10. M. Lertcanawanichakul, Int. J. Pharma. Bio. Sci., 6, 1089 (2015).

11. R. Benigni and C. Bossa, Mutat. Res., 659, 248 (2008); doi:10.1016/j.mrrev.2008.05.003.

12. D.R. Wessner, P.C. Maiorano, J. Kenyon, R. Pillsbury and A.M. Campbell, (2000), Spot- overlay Ames test of potential mutagens. Available from: http://www.zoo.utoronto.ca/able.

13. K. Mortelmans and E. Zeiger, Mutat. Res., 455, 29 (2000); doi:10.1016/S0027-5107(00)00064-6.

14. B.N. Ames, W.E. Durston, E. Yamasaki and F.D. Lee, Proc. Natl. Acad. Sci. USA, 70, 2281 (1973); doi:10.1073/pnas.70.8.2281.

15. B.N. Ames, J. McCann and E. Yamasaki, Mutat. Res., 31, 347 (1975); doi:10.1016/0165-1161(75)900461 .

16. D.M. Maron and B.N. Ames, Mutat. Res., 113, 173 (1983); doi:10.1016/0165-1161(83)90010-9.

17. M.M. Bradford, Anal. Biochem., 72, 248 (1976); doi:10.1016/0003-2697(76)90527-3.

18. C. Changsen, S.G. Franzblau and P. Palittapongarnpim, Antimicrob. Agents Chemother., 47, 3682 (2003); doi:10.1128/AAC.47.12.3682-3687.2003.

19. L.A. Collins, M.N. Torrero and S.G. Franzblau, Antimicrob. Agents Chemother., 42, 344 (1998).

20. F.V. Santos, I.M.S. Colus, M.A. Silva, W. Vilegas and E.A. Varanda, Food Chem. Toxicol., 44, 1585 (2006); doi:10.1016/j.fct.2006.03.012.

21. N. Krebsfaenger, (2010), Ames test: Bacterial Reverse Mutation Assay. Available from: www.genpharmtox.com.

22. L. Opašić, M. Zajc, C. Virapin, E. Petelin and A. Stafa, (2006), The Ames mutagenicity testing mutations in reverse gear. Available from: www.astro.hr/s3/izvjestaji/s3pp2009/WebReportAmesTest.pdf.

23. M. Oskay, Int. J. Agric. Biol., 13, 317 (2011).

24. H. Ren, P. Zhang, C. Liu, Y. Xue and B. Lian, World J. Microbiol. Biotechnol., 26, 465 (2010); doi:10.1007/s11274-009-0192-2. 
Monthon Lertcanawanichakul et al/International Journal of PharmTech Research, 2017,10(2): 89-95. 95

25. D. Sharma, S.M. Mandal and R.K. Manhas, AMB Express, 4, 50 (2014); doi:10.1186/s13568-014-0050-y.

26. D.V.R.N. Bhikshapathi, D.R. Krishna and V. Kishan, Indian J. Biotechnol., 9, 265 (2010).

$* * * * * \quad * * * * *$ 